\title{
A Study on Miracles through Holy Bible using Combined Overlap Block Fuzzy Cognitive Maps (COBFCMS)
}

\author{
A. Victor Devadoss \\ Professor \\ Loyola College \\ Chennai -600034
}

\author{
A. Rajkumar \\ Assistant Professor \\ Hindustan University \\ Chennai - 603103
}

\author{
N. Jose Parvin Praveena \\ Assistant Professor \\ KCG College of Technology, \\ Chennai -600097
}

\begin{abstract}
The Imperative reasons for miracles through Holy Bible using combined overlap block fuzzy cognitive maps (COBFCMS) defined by W.B Vasantha Kandasamy is analyzed in this paper. The combined overlap block FCM's defined in this method become effective when the number of concepts can be grouped and are large in numbers. In this paper we analyzed the miracles and are large in number. In this paper we analyzed the miracles and find out the reasons how it is happened to people. This paper has six sections, first section gives the information about development of fuzzy cognitive maps, second section gives preliminaries of fuzzy cognitive maps, and combined overlap block fuzzy cognitive maps, in section three we explain about the miracles in bible, in section four we explain the method of determining their hidden pattern, in section five, we give the concept of the problem, final section gives the conclusion based on our studies.
\end{abstract}

Index Terms - FCMS, COBFCMS, Bible.

\section{INTRODUCTION}

Political scientist R.Axelrod[1] introduced cognitive maps for representing social scientific knowledge and describing the methods that are used for decision making in social and political systems. Then B. Kosko [2,3,4] enhanced the power of cognitive maps considering fuzzy values for the concepts of the cognitive map and fuzzy degrees of interrelationships between concepts. FCMs can successfully represent knowledge and human experience, introduce concept to represent the essential elements and cause the effect relationships among the concepts to model the behavior of any system. It is a very convenient, simple and powerful tool, which is used in numerous fields such as social economic and medical etc. the purpose of study is to identify risk groups, miracle is an event that apparently contradicts known scientific laws and is hence thought to be due to supernatural causes especially to an act of god miracles in the new testament had a purpose , miracles were performed to confirm the word (Mark 16:20), produce faith in Jesus Christ (John 20: 30-31) shows that god is with Jesus (John 3:2),demonstrate that jesus is the Christ ,the son of god, as prophesied (Matt 8:16-17).The New Testament relates about thirty five miracles performed by Jesus. The miracles can be classified as miracles of nature, miracles of healing and miracles of resurrection. Moreover the data is an unsupervised one and also there is uncertainty in the concepts.

Hence fuzzy tools alone has the capacity to analyze these concepts. Hence it is chosen here.

\section{PRELIMINARIES}

Fuzzy cognitive maps (FCMs) are more applicable when the data in the first place is an unsupervised one. The FCMs work on the opinion of experts. FCMs model the worlds as a collection of classes and causal relation between classes.

Definition 2.1: An FCM is a directed graph with concepts like policies, events etc. As nodes and causalities as edges. It represents causal relationship between concepts.

Definition 2.2: When the nodes of the FCM are fuzzy sets then they are called as fuzzy nodes.

Definition 2.3: FCMs with edge weights or causalities from the set $\{-1,0,1\}$ are simple.

Definition 2.4: The edges $e_{i j}$ take values in the fuzzy causal interval $[-1,1] . \mathrm{e}_{\mathrm{ij}}=0$ indicates no causality $\mathrm{e}_{\mathrm{ij}}>0$ indicates causal increase $C_{j}$ increases as $C_{i}$ increases $\left(\right.$ Or $C_{j}$ Decreases as $C_{i}$ Decreases). $E<0$ indicates causal decrease or negative causality. C Decreases as $\mathrm{C}$ increases (And or $\mathrm{C}_{\mathrm{j}}$ increases as $C_{i}$ Decreases). Simple FCMs have edge values in $\{-1,0,1\}$. Then if causality occurs, It occurs to a maximal positive or negative degree. Simple FCMs provide a quick first approximation to an expert stand or printed causal knowledge. If increase (Or decrease) in one concept leads to increase (or decrease) in another, Then we give the value 1.If there exists to relation between the two concepts, The value 0 is given. If increase (or decrease) in one concept decreases (or increases) another, then we give the value -1 . Thus FCMs are described in this way. Consider the or concepts $C_{1}, \ldots, C_{n}$ of the FCM. Suppose the directed graph is drawn using edge weight $\mathrm{e}_{\mathrm{ij}} \in$ $\{0,1,-1\}$. The matrix $E$ be defined by $E=\left(e_{i j}\right)$, Where the $e_{i j}$ is the weight of the directed edge $C_{i}, C_{j}$. E is called the adjacency matrix of the FCM, also known as the connection matrix of the FCM. It is important to note that all matrices associated with an FCM are always square matrices with diagonal entries as zero.

Definition 2.5: Let $C_{1}, C_{2}, \ldots . C_{n}$ be the nodes of an FCM. Let $A=\left(a_{1}, a_{2}, \ldots, a_{n}\right)$, where $a_{i} \in\{0,1\} . A$ is called the instantaneous state vector and it denoted the on off position of the node at an instant
$\mathrm{a}_{\mathrm{i}}=0$
if $a_{i}$ is off $=1$
$\mathrm{a}_{\mathrm{i}}=1$
if $a_{i}$ is on, where $i=1,2, \ldots, n$. 
Definition 2.6: Let $\mathrm{C}_{1}, \mathrm{C}_{2}, \ldots, \mathrm{C}_{\mathrm{n}}$ be the nodes of an FCM. Let $C_{1} C_{2}, C_{2} C_{3}, \ldots, C_{i} C_{j}$, be the edges of the FCM ( $i \neq j$ ). Then, the edges form a directed cycle. An FCM s said to be cyclic if it possesses a directed cycle. An FCM is said to be a cyclic if it does not possess any directed cycle.

Definition 2.7: An FCM with cycles is said to have a feedback.

Definition 2.8: Where there is a feedback in an FCM, i.e., When the causal relations flow through a cycle in a revolutionary way, The FCM is called a dynamical system.

Definition 2.9: Let $C_{1} C_{2}, C_{2} C_{3}, \ldots, C_{i} C_{j}$, be a cycle when $C_{i}$ is switched on and if the causality flows through the edges of a cycle and if it again causes $\mathrm{C}_{\mathrm{i}}$, We say that the dynamical system goes round and round. This is true for any node $C_{i}$, for $\mathrm{i}=1,2, \ldots, \mathrm{n}$. The equilibrium state for this dynamical system is called the hidden pattern.

Definition 2.10: If the equilibrium state of a dynamical system is a unique state vector, Then it is called a fixed point. Consider a FCM with $\mathrm{C}_{1}, \mathrm{C}_{2}, \ldots, \mathrm{C}_{\mathrm{N}}$ as nodes. For example let us start the dynamical system by switching on $\mathrm{C}$. Let us assume that the FCM settles down with $C_{1}$ and $C_{n}$ on, i.e. the state vector remains as $(1,0,0, \ldots, 0,1)$. This state vector $(1,0,0, \ldots, 0,1)$ is called the fixed point.

Definition 2.11: If the FCM settles down with a state vector repeating in the form $A_{1} \rightarrow A_{2} \rightarrow \ldots A_{I} \rightarrow A_{1}$. Then this equilibrium is called limit cycle.

Definition 2.12: Finite number of FCMs can be combined together to produce the joint effect of all the FCMs. Let $E_{1}$, $\mathrm{E}_{2}, \ldots, \mathrm{E}_{\mathrm{p}}$ be adjacency matrices of the FCMs with nodes $\mathrm{C}_{1}$, $\mathrm{C}_{2}, \ldots, \mathrm{C}_{\mathrm{n}}$. Then the combined FCM $[5,6,7]$ is got by adding all the adjacency matrices $\mathrm{E}_{1}, \ldots, \mathrm{E}_{\mathrm{p}}$. We denote the combined $\mathrm{FCM}$ adjacency matrix by $\mathrm{E}=\mathrm{E}_{1}+\mathrm{E}_{2}+\ldots+\mathrm{E}_{\mathrm{p}}$.

Definition 2.13: Let $P$ be the problem under investigation. Let $\left\{\mathrm{C}_{1}, \mathrm{C}_{2}, \ldots, \mathrm{C}_{\mathrm{n}}\right\}$ be $\mathrm{n}$ concepts associated with $\mathrm{p}$ ( $\mathrm{n}$ very large). Now divide the number of concepts $\left\{C_{1}, C_{2}, \ldots, C_{n}\right\}$ into classes $S_{1}, \ldots, S_{t}$ where classes are such that

(1) $\mathrm{S}_{\mathrm{i}} \cap \mathrm{S}_{\mathrm{i}+1} \neq \phi$ where $(\mathrm{i}=1,2, \ldots, \mathrm{t}-1)$

(2) $\cup \mathrm{s}_{\mathrm{i}}=\left(\mathrm{c}_{1}, \ldots, \mathrm{c}_{\mathrm{n}}\right)$

(3) $\left(s_{i}\right) \neq s_{j} \quad$ if $i \neq j$ in general

Now we obtain the FCM associated with each of the classes $\mathrm{S}_{1}, \ldots, \mathrm{S}_{\mathrm{t}}$. We determine the relational matrix associated with each $\mathrm{S}$. Using theses matrices we obtain a $\mathrm{n} \times \mathrm{n}$ matrix. This $\mathrm{n} \times \mathrm{n}$ matrix is the matrix associated with the combined overlap block FCM (COBFCM) of blacks of same sizes.

Definition 2.14: Suppose $A=\left(a_{1}, \ldots, a_{n}\right)$ is a vector which is passed into a dynamical system $E$. Then $A E=\left(a_{1}^{\prime}, \ldots, a_{n}^{\prime}\right)$. After thresholding and updating the vectors suppose we get $\left(b_{1}, \ldots, b_{n}\right)$. We denote that by $\left(a_{1}^{\prime}, a_{2}^{\prime}, \ldots, a_{n}^{\prime}\right) \rightarrow\left(b_{1}, b_{2}, \ldots, b_{n}\right)$. Thus the symbol $\rightarrow$ means that the resultant vector has been thresholded and updated. FCMs have several advantages as well as some disadvantages. The main advantage of this method it is simple. It functions on experts opinion's. When the data happens to be an unsupervised one the FCM comes handy. This is the only known fuzzy technique that gives the hidden pattern of the situation. As we have a very well known theory, which states that the strength of the data depends on the number of experts opinions we can use combined FCMs with several experts opinions. At the same time the disadvantage of the combined FCM is when the weightages are 1 and -1 for the same $C_{i} C_{j}$. We have the sum adding to zero thus at all times the connection matrices $\mathrm{E}_{1}, \ldots, \mathrm{E}_{\mathrm{k}}$ may not be comfortable for addition. This problem will be easily overcome if the FCM entries are only 0 and 1 .

\section{A STUDY ON MIRACLES THROUGH HOLY BIBLE USING COBFCMS}

For that, using linguistic questionnaire and the expert's opinion we have taken the following eleven concepts $\left\{C_{1}\right.$, $\left.\mathrm{C}_{2}, \ldots, \mathrm{C}_{9}\right\}$

The following concepts are taken as the main nodes for our problem.

Release of miracles through the power of Jesus

$\mathrm{C}_{1}$ - Endurance through prayer

$\mathrm{C}_{2}$ - Faith

$\mathrm{C}_{3}$ - Humility

$\mathrm{C}_{4}$ - Repentance

$\mathrm{C}_{5}$ - Obedience

$\mathrm{C}_{6}$ - Hearing the word of god

$\mathrm{C}_{7}$ - Authority in the spiritual realm

$\mathrm{C}_{8}$ - God's Compassion

$\mathrm{C}_{9}$-love

$C_{1}$ - Perseverance through prayer

Perserverance is anything undertaking continued pursuit or prosecution of any business or enterprise begin, in theology, persistence means continuance in a state of grace to a state of glory.

\section{$\mathrm{C}_{2}$-Faith}

Faith refers to the trust one puts in god at all times. It is total surrender to god with full belief without any need for logical proof or material evidence, faith makes us to encounter god directly, it demands to place our full trust in god.

\section{$\mathrm{C}_{3}$-Humility}

Humility is the prerequisite for honor (Prov 15:33; 18:12; 22:4; 29:23 ) and physical blessing (Psalm 37:11; Matt 5:5) Intimately associated with the fear of the Lord (Psalms 25:9 Psalms 25:12-14; Prov 15:33), it may provide the key to wealth and life (Prov 22:4); but even when blessings are postponed, a humble spirit is necessary (Prov 16:18-19; cf. Romans 12:14 Romans 12:16-17). It is the gateway to eternal life (Matt $5: 3 ; 18: 1-4$ ), not necessarily physical reward (5:10-12).

\section{$\mathrm{C}_{4}$-Repentance}

Repentance is a change of heart repentance infuses a deep sense of humility in people repentance brings about inner 
healing, it takes up the broken chains of communication with god and with one another on a sound footing.

\section{$\mathrm{C}_{5^{-}}$-Obedience}

Obedience refers to being ready to subject ourselves to the commands, wishes and guidelines of others. Obedience teaches us to deny ourselves. It prompts to act in accordance with another wish .obedience gives moral and spiritual power and strength to command. The more one obeys the more one rule.

\section{$\mathrm{C}_{6}$ - Hearing the word of god}

The Bible claims to be the Word of God and by staking this claim the Bible simply but plainly declares its divine authority, complete infallibility and absolute sufficiency.

\section{$\mathrm{C}_{7}$ - Authority in the spiritual realm}

The authority that the lord gives to his church-spiritual authority (not in the natural realm but spiritual.

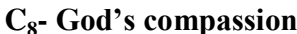

It simply says that compassion means sympathetic consciousness of others' distress along with a desire to alleviate it.

\section{$\mathrm{C}_{9}$-Love}

Love urges us to diffuse its fragrance on others love triggers off an emotional response leading to action.

\section{METHOD OF DETERMINING HIDDEN PATTERN}

Let $\mathrm{C}_{1}, \mathrm{C}_{2}, \ldots, \mathrm{C}_{\mathrm{n}}$ be the nodes of an FCM, With feedback. Let $\mathrm{E}$ be the associated adjacency matrix. Let us find the hidden pattern when $C_{1}$ is switched on. When an input is given as the vector $A_{1}=(1,0,0, \ldots, 0)$, the data should pass through the relation matrix $E$. this is done by multiplying $A_{1}$ by the matrix $E$. Let $A_{1} E=\left(a_{1}, \ldots, a_{n}\right)$ with the threshold operation that is by replacing $a_{i}$ by 1 if $a_{i}>k$ and $a_{i}$ by 0 if $a_{i}$ $<\mathrm{k}$ ( $\mathrm{k}$ is a suitable positive integer). We update the resulting concept, The concept $\mathrm{C}_{1}$ is included in the updated vector by making the first coordinate as 1 in the resulting vector. Suppose $\mathrm{A}_{1} \mathrm{E} \rightarrow \mathrm{A}_{2}$ then consider $\mathrm{A}_{2} \mathrm{E}$ and repeat the same procedure. This procedure is repeated till we get a limit cycle or a fixed point.

\section{CONCEPT OF THE PROBLEM}

Using the linguistic questionnaire and the expert's opinion we have taken the following nine concepts $\left\{\mathrm{C}_{1}, \mathrm{C}_{2}, \ldots, \mathrm{C}_{9}\right\}$

$\mathrm{C}_{1}$ - Endurance through prayer

$\mathrm{C}_{2}$ - Faith

$\mathrm{C}_{3}$ - Humility

$\mathrm{C}_{4}$ - Repentance

$\mathrm{C}_{5}$ - Obedience

$\mathrm{C}_{6}$ - Hearing the word of god

$\mathrm{C}_{7^{-}}$Authority in the spiritual realm

$\mathrm{C}_{8}$ - God's Compassion

$\mathrm{C}_{9}$-love

Now we proceed on to apply the effect of combined overlap block. FCM of equal length. Let us consider the eleven concepts $\left\{\mathrm{C}_{1}, \mathrm{C}_{2}, \ldots, \mathrm{C}_{9}\right\}$. We divide these concepts into cyclic way of classes, each having just four concepts in the following way.
1. The directed graph and the relation matrix for the class $\mathrm{C}=\left\{\mathrm{C}_{2}, \mathrm{C}_{7}, \mathrm{C}_{8}, \mathrm{C}_{4}\right\}$. The expert opinion of an expateriot of religious churches is given as follows:

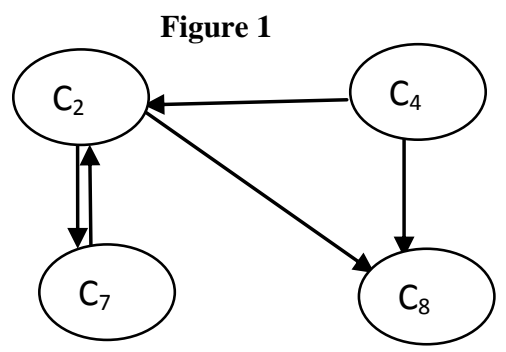
$\begin{array}{llll}\mathrm{C}_{2} & \mathrm{C}_{4} & \mathrm{C}_{7} & \mathrm{C}_{8}\end{array}$
$\mathrm{C}_{4}\left[\begin{array}{cccc}0 & 0 & 1 & 1 \\ \mathrm{C}_{7} & 0 & 0 & 1 \\ \mathrm{C}_{8} & 0 & 0 & 0 \\ 1 & 0 & 0 & 0\end{array}\right]$

2. The directed graph and the relational matrix for the class $\mathrm{C}=\mathrm{C}_{1}, \mathrm{C}_{2}, \mathrm{C}_{3}, \mathrm{C}_{8}$ \}. Given by the expert is as follows: (Religious NGO)

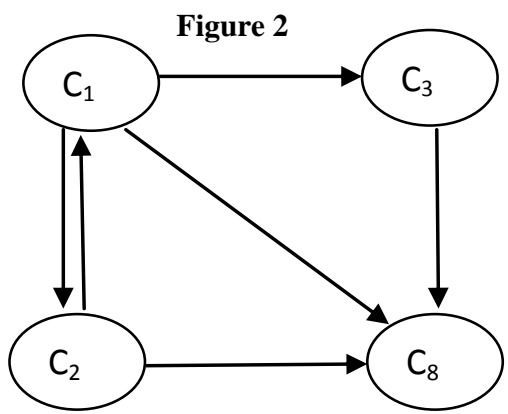

$$
\begin{array}{llll}
\mathrm{C}_{1} & \mathrm{C}_{2} & \mathrm{C}_{3} & \mathrm{C}_{8}
\end{array}
$$

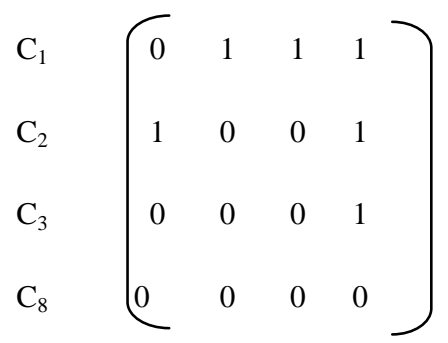

3. The directed graph and the relational matrix for the class $\mathrm{C}=\left\{\mathrm{C}_{4}, \mathrm{C}_{5}, \mathrm{C}_{6}, \mathrm{C}_{8}\right\}$. Given by the expert is as follows: Priest, 
Figure 3

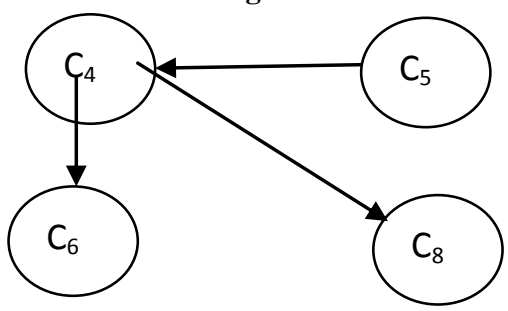

$\begin{array}{lllll}\mathrm{C}_{4} & \mathrm{C}_{5} & \mathrm{C}_{6} & \mathrm{C}_{8}\end{array}$



The directed graph and the relation matrix for the class $\mathrm{C}$ $=\left\{\mathrm{C}_{2}, \mathrm{C}_{6}, \mathrm{C}_{8}, \mathrm{C}_{9}\right\}$ Given by the expert is as follows: students from bible college

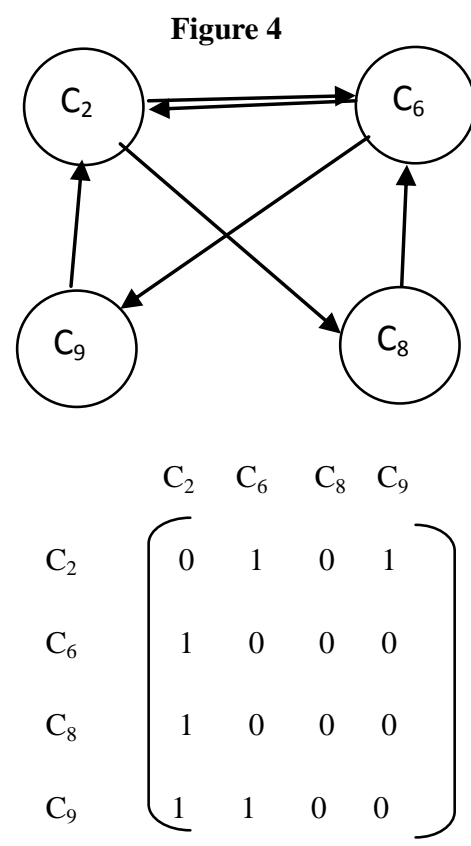

The directed graph and the relational matrix for the class $\mathrm{C}=$ $\left\{\mathrm{C}_{4}, \mathrm{C}_{5}, \mathrm{C}_{8}, \mathrm{C}_{9}\right\}$. Given by the expert is as follows:

A believer Figure 5

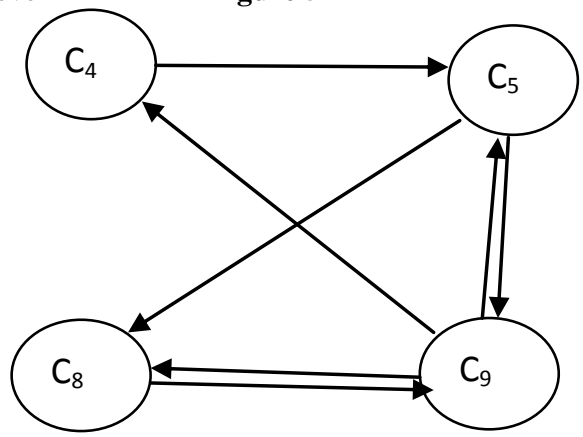

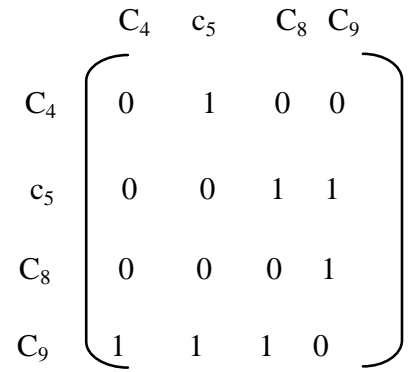

The combined direct graph and combined overlap block FCM of equal sizes as follows

Figure 6

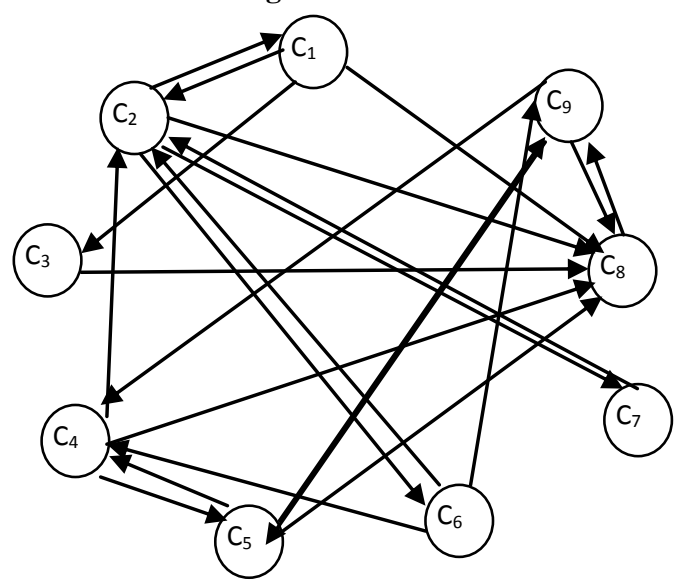

$\mathrm{C}(\mathrm{m}) \mathrm{C}_{1} \quad \mathrm{C}_{2} \quad \mathrm{C}_{3} \quad \mathrm{C}_{4} \quad \mathrm{C}_{5} \quad \mathrm{C}_{6} \quad \mathrm{C}_{7} \quad \mathrm{C}_{8} \quad \mathrm{C}_{9}$

$\left.\begin{array}{l|lllllllll}\mathrm{c}_{1} & 0 & 1 & 1 & 0 & 0 & 0 & 0 & 1 & 0 \\ c_{2} & 1 & 0 & 0 & 0 & 0 & 0 & 1 & 3 & 0 \\ c_{3} & 0 & 0 & 0 & 0 & 0 & 0 & 0 & 1 & 0 \\ c_{4} & 0 & 1 & 0 & 0 & 1 & 0 & 0 & 2 & 0 \\ c_{5} & 0 & 0 & 0 & 1 & 0 & 0 & 0 & 1 & 1 \\ c_{6} & 0 & 1 & 0 & 1 & 0 & 0 & 0 & 0 & 1 \\ c_{7} & 0 & 1 & 0 & 0 & 0 & 0 & 0 & 0 & 0 \\ c_{8} & 0 & 0 & 0 & 0 & 0 & 0 & 0 & 0 & 2 \\ c_{9} & 0 & 0 & 0 & 1 & 1 & 0 & 0 & 2 & 0\end{array}\right)$

Now using the matrix A of the combined overlap block FCM, We determine the hidden pattern. Suppose the concept $S_{1}$ is in the on state and another nodes are in the off sate. Let the

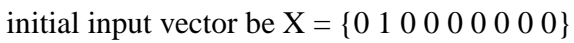

$\mathrm{X} C(\mathrm{~m})=\left\{\begin{array}{llllllllll}1 & 0 & 0 & 0 & 0 & 0 & 1 & 3 & 0\end{array}\right\}=\mathrm{X}_{1}$

$\mathrm{X}_{1} \mathrm{C}(\mathrm{m})=\left\{\begin{array}{llllll}0 & 21000010\end{array} \rightarrow\{011000010\} X_{2}\right.$

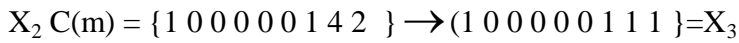

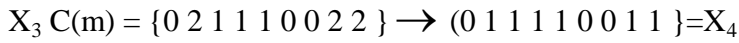

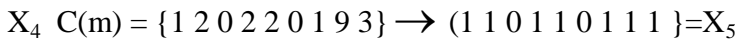
$\mathrm{X}_{5} \mathrm{C}(\mathrm{m})=\left(\begin{array}{lll}13 & 1220193\end{array}\right) \rightarrow\left(\begin{array}{ll}1 & 111110111\end{array}\right)=\mathrm{X}_{6}$ $\left.\mathrm{X}_{6} \mathrm{C}(\mathrm{m})=(141320193\} \rightarrow(111110111\}\right)$ 
Where $\rightarrow$ Denotes the resultant vector after thresholding and updating.

$\mathrm{X}_{6}$ is the hidden pattern which is the fixed point.

\section{CONCLUSION}

While analyzing FCM, When the concept $\mathrm{C}_{2}$ "Faith is in the on state, the other concepts $\mathrm{C}_{1}, \mathrm{C}_{3}, \mathrm{C}_{4}, \mathrm{C}_{5}, \mathrm{C}_{7}, \mathrm{C}_{8}, \mathrm{C}_{9}$, are in the on state, but $\mathrm{c}_{6}$ are in the off state. Each and every person need faith to get miracles from god. Faith can be cultivated through

1. Raising our mind to god

2. Turning our attention away from self

3. Forgiving others

4. Helping others in need

5. Persisting in our prayer

6. Believing in god's providence.

7. Accepting our weakness and sinfulness.

8. Look back -he's our creator (Col.1:16)

9. Look ahead -he's our judge(2 Cor .5:10)

10. Look up -he's savior and lord (Phil 2.5-11)

11. Look down -he's our sustainer (Col.1:17)

12. Look right -he's our teacher (Mt.23:8)

13. Look left -he's our advocate (1 Jn.2:1)

14. Look within-he's our life (Gal.2:20)

\section{FUTURE WORK}

Faith will be measured by using fuzzy model.

\section{ACKNOWLEDGMENT}

The authors wish to thank A. Praveen Prakash and Jayalatha.

\section{REFERENCES}

[1] Axelrod,R.(1976).Structure of decision :The congnitive maps of political elites. Princeton University.

[2] Vasantha Kandasamy W.B and Victor Devadoss A. "Some New Fuzzy Techniques", Jour.of inst.of Math \& Computer science.

[3] Kosko,B., "Fuzzy Cognitive Maps", International Journal of man-machine studies, Jan(1986)

[4] Kosko, B. 1997 Neural Networks and Fuzzy System Prentice Hall of India.
[5] Kosko ,B. Hidden patterns in Combined and adaptive Knowledge Networks,International Conference of Neural Networks(ICNN-86)1988 377-393.

[6] The Holy Bible -The bible society of india-ISBN81-2210246-8

[7] Change of quality of life through literacy in Bhutan using Fuzzy cognitive mapping by Victor Devadoss

[8] Vasantha Kandasamy W.B and M.Ram Kishore Symptom-Disease Model in Children using FCM, Ultrasci.11(1999)318-324.

[9] Adaptation of induced fuzzy cognitive maps to the problem faced by the power loom workers by s.narayanamoorthy and s.kalaiselvan

[10] Narayanamoorthy. S, Shanmugam. P. Application of Fuzzy Networks to Analyze the Socio - Economic Problems Faced by Cotton Mill Workers. International Journal of Mathematics and Computation, 2011, pp.2832.

[11] Oddvar Hollup. Bonded Labour. Sterling Publishers Private Limited, 1994, New Delhi, India.

[12] Ritha. W, Mary Mejrullo Merlin. M. Predictors of interest in cosmetic surgery-An analysis using induced fuzzy cognitive maps(IFCMs). Annals of Fuzzy Mathematics and Informatics, (2) 2011,pp.161-169

[13] Taber, W.R., and Seigel, M. Estimation of Expert Weights with Fuzzy Cognitive Maps, Proceedings of the $1^{\text {st }}$ IEEE International Conference on Neural Networks (ICNN-87), v2, 1987, pp.319-325.

[14 Taber, W.R., Fuzzy Cognitive Maps Model Social Systems, AI Expert, v9, 1994, pp.18-23.

[15] Zedah, L.A., Fuzzy Sets, information and Control, V8, 1965, pp.338-353.

[16] Vasantha Kandaswamy, W.B, and Anitha, V.Studies on Female Infanticide problem using Neural Networks BAM Model. Ultra Sci., v13, 2001, pp. 174-183.

[17] Vasantha Kandaswamy , W.B., Anthony Raj, S., and Victor Devadoss, A., Some new fuzzy techniques, Journal of Math \& Comp. Sci. (Math.seer), V17, No.2, 2004, pp. $157-160$. 